\title{
The Continuity of Disability, Diversity and Personalisation: an Emerging Challenge for $\mathrm{HCl}$
}

\author{
Sebastiano Bagnara ${ }^{1}$ and Simone Pozzi ${ }^{2}$ \\ ${ }^{1}$ Faculty of Architecture, University of Sassari, Alghero, Italy \\ ${ }^{2}$ Dept. of Communication Sciences, University of Siena, Italy E Deep Blue, Rome, Italy
}

\section{Introduction}

In the famous short novel "The Country of the Blind", H.G. Wells describes an isolated community, whose members have become blind long ago. The blind men have entirely redesigned their village to suit their blindness: sensory paths radiate from the village centre to the fields, houses are windowless to better protect from heat and from cold, the villagers have even changed their circadian rhythms, as they work at night when there is no sun heat. One day a traveler, named Nunez, arrived in this village. After discovering the blindness of the inhabitants, Nunez started thinking that "in the country of the blind the one-eyed man is king". He thought he would eventually rule the village because of his superiority, because he could see. However, Nunez soon discovered that the sense of sight was not highly valued by the blind villagers. They no longer had a concept for sight and their village had been shaped in such a manner that Nunez could not demonstrate any practical advantage over them. Indeed, he found himself to be the disadvantage one. He was not able to see where to walk inside the dark windowless houses and kept stumbling. He could not become a member of the community because he was still able to see.

The story of Wells illustrates some subtle aspects of the relationship between disability and human activity:

- Disability is related to a specific setting and to a specific activity (e.g. windowless houses and night work). There are "objective" physical, cognitive and social abilities/impairments, but disability is better thought of as the outcome of these in relation to an external setting and activity. Limitations are engendered by the relation between (i) our physical, cognitive and social characteristics, (ii) the activity to be carried out and (iii) the setting.

- A well-thought design of the setting (i.e. of assistive tools) can overcome what we would expect to be our limitations. Humans are able to exploit external tools to overcome their impairments and achieve a proficient performance.

- Being a relational concept, disability is more a statistical measure of the "standard relation" between human characteristics and the activity, than an "objective" parameter. Instead of being the king, Nunez is the disabled one in the country where everyone is blind. 
Our paper moves from these points to reflect on the relationship between HCI and disability. We propose to consider disability not as an isolated niche of $\mathrm{HCI}$ study. It is rather part of a more general challenge, that $\mathrm{HCI}$ is facing as a discipline in its applications and studies (a similar claim can be found in Lewis, 2006). Our claim is that HCI is not yet fully equipped to cope with the increased complexity and variety of our technological life, of which disability is only a specific part.

\section{Dovetailing and internalisation}

The field of HCI studies on disability has definitively certain peculiarities. HCI researchers do need to study the nature and causes of specific physical or cognitive conditions, in order to design user-friendly technologies. But it also shares the basic goal of the general HCI endeavor "Human-computer interaction is a discipline concerned with the design, evaluation and implementation of interactive computing systems for human use and with the study of major phenomena surrounding them" (Association for Computing Machinery, 2008).

At the core of HCI studies is indeed the special relationship that we as humans are able to establish with technological devices. As well put by Andy Clark (Clark, 2003), humans are increasingly becoming "natural-born cyborgs". Key concept in his reasoning is the one of 'dovetail'. By interacting with tools and external elements, we put our cognitive skills in connection with these external elements, to form a new unity, new cognitive skills, new abilities, where it is hard (and not very meaningful) to distinguish between the contribution of our mind and that of external tools. "Ours are essentially the brains of natural-born cyborgs, ever-eager to dovetail their activity to the increasingly complex technological envelopes in which they develop, mature, and operate" (pg. 26).

On the same line of thought, we should also mention the Distributed Cognition approach (Hutchins, 1995; Norman, 1988). While mainstream cognitive science sees human cognition as happening inside the heads of individual actors, Distributed Cognition describes cognition as happening in the fabric of 'human-external world' interactions. In particular, Distributed Cognition has studied how people modify the external environment to save attention, memory and computational efforts. They recruit external elements to reduce their own cognitive effort (Kirsh, 1995), they produce pre-computed solutions (e.g. tools and procedures) to frequently encountered problems and preserve these solutions through cultural transmission (Hutchins, 1995).

Behind such approaches lies a theoretical tenet that has gained momentum since the eighties, as a reaction to the cognitive revolution of the fifties. It claims that cognition is not only in our head, but results from the connection between our head and the external world, in particular between our cognition and our tools.

We all have experienced the sensation of a tool becoming transparent to our perception. It becomes so part of our daily life, that we no longer perceive it as an external device. This happens for very simple tools (e.g. a hammer, sport equipments, a pen, etc.), as well as for more complex devices (e.g. computers, mobile devices, clutch and pedals in our car, etc.). Noticeably, blindness was again taken as an example to elaborate on this concept by Bateson in a very famous excerpt: "Suppose I am a blind man, and I use a stick. I go tap, tap, tap. Where do I start? Is my mental system bounded at the handle of the stick? Is it bounded by my skin? Does it start halfway up the stick? Does it start at the tip of the stick? But these are 
nonsense questions. The stick is a pathway along which transforms of difference are being transmitted. The way to delineate the system is to draw the limiting line in such a way that you do not cut any of these pathways in ways which leave things inexplicable. If what you are trying to explain is a given piece of behaviour, such as the locomotion of the blind man, then, for this purpose, you will need the street, the stick, the man; the street, the stick, and so on, round and round. But when the blind man sits down to eat his lunch, his stick and its messages will no longer be relevant-if it is his eating that you want to understand" (Bateson, 1972, p. 434). However, we also know that too often a tool gets in our way while we try to perform a certain task, e.g. troubleshooting our word processor, pc and printer is a good example of tools getting between us and our goal.

These two polarities of human-tool interaction can be summarised in two categories first introduced by Heidegger: 'ready-to-hand' and 'present-at-hand' (Heidegger, 1927/1962, cited in Chalmers, 2004). Ready-to-hand tools are transparent when we use them, "literally visible, effectively invisible" (Weiser, 1994a, p. 1). They are dovetailed with our cognition. Present-at-hand tools concern us not because we are using them, but because we are consciously observing and analysing them. A tool like a hammer may become present-athand when it breaks and loses its usefulness, or at the first encounter, when we do not know how to interact with it.

These two poles may be conceived as separate, but reality is that we continuously move between the two poles in our daily activity. Tools become ready-to-hand usually after some usage, they may revert to present-at-hand in case of breakdowns in the activity and, to a certain extent, the more we shift between the two modes, the more we are able to effectively master a tool and make it fully transparent in our activity. In order to understand these two modes of human-tool interaction we need to conceive the interaction as a process, with learning and development taking place through practice.

When a tool becomes ready-to-hand, it does not only disappear from our awareness. It also re-structures the way we think and the way we see the world. It becomes part of our cognition, in the sense that we begin perceiving the world and thinking of possibilities of action through the tool's affordances. This process has been described by Vygotsky in his cultural-historical approach (Vygotsky, 1978, 1986), by analysing the internalisation process. Oversimplifying for clarity's sake, Vygotsky's "General Law of Cultural Development" states that subjects internalise external tools (material and non material ones, like language and signs) and form analogue cognitive functions inside their brains. For instance, the process of thinking is formed by the progressive internalisation of speaking.

The key common point in the above discussion is that of brain plasticity. As a product of their functioning, our brains internalise tools. Our tools become part of our brain. It is not something we have to try hard for, it is like second nature. And it applies to any tool.

This is a challenge for HCI: how to design tools that effectively dovetail with our cognition? Certainly by supporting both ways of functioning, i.e. ready-to-hand and present-at-hand. I may prefer not being aware of the tool when using it, but I definitively have to understand its way of working at the first use, or if I want to avoid/solve breakdowns. Even though some design approaches (Dourish, 2001; Weiser, 1991) have advocated a decisive move in the direction of invisible tools ("a good tool is an invisible tool", Weiser, 1994b), we maintain that both modes are necessary for good HCI. As well put by Norman, a tool is user-friendly as long as the designer makes clear its way of functioning to the user, thus bridging the gap between the user's mental model and the actual system model (Norman, 1988). In order to 
do that, the user needs to shift continuously between experiential cognition (ready-to-hand) and reflexive one (present-at-hand).

\section{Changes in the nature of work}

$\mathrm{HCI}$ is an applied science, whose objectives reflect the changing priorities of human societies. In its history, Ergonomics (the direct father of $\mathrm{HCI}$ ) has always tackled those issues that mostly mattered to its contemporary societies: physical ergonomics and work related diseases in the Tayloristic era, selection and training during the Second World War, human error in nuclear power plants and aviation in the Eighties, to name but a few. HCI has flourished during the 'information revolution', when the Tayloristic era came to its end, and computers became central to our everyday life. Indeed, most of today work is very far from that of twenty-five years ago. At that time, industrial work prevailed: it was very simple, usually performed in dedicated place, permanent, repetitive, and boring. It did not require mental effort, and was predominantly manual. Clerical work was similar, even though implied routinary mental, rather than manual, work.

If we are to understand the role HCI can play in designing assistive technologies, we need to reflect on the changing characteristics of modern societies. Ergonomics itself has moved from a science of correction (correct and eliminate work related problems), to a science of compatibility (design systems so that they are compatible with humans' limitations), to being primarily concerned with the notion of 'fit' (design man-machine systems so that the various elements best fit with each other).

The actual prevailing form of work shows some striking features (Malone, 2004; National Research Council, 1999). From the demographical point of view work is heterogeneous. The diversity in human resources is growing in terms of gender, race, education, culture and status. Communication has become a key topic to keep such heterogeneity organised.

Work is becoming more dynamic and boundaries among various jobs have become weak and permeable (Davis \& Meyer, 1998). Jobs are often complementary and affect each other. Many workers are engaged in more parallel tasks, sometimes exploiting different competencies. However, new work forms tend to rely on the same technological infrastructure. Compared to the Tayloristic era, today's workplaces are more similar, all implying the use of a personal computer. Another key difference is that no one could have taken home her/his working tools from the Tayloristic factory, while working tools are now part of our houses and of our personal life. Nowadays, it is possible to work at home: technology is everywhere, and employers expect people to have the skills required to manage this technology. Those who lack these skills are at risk of being cut off from work. This digital divide is not limited to work but is also present in everyday life and affects people's social relations.

Work is differentiated. The supply side is no longer setting the pace of the market. The demand side is doing it. Contrary to the supply side, demand is driven by desires, thus differentiated by nature and changing rapidly. Work has to cope with such variability. Work aim is to deliver novelty and innovation, thus constantly requiring novel activities in uncertain conditions (Bauman, 2000).

Work is socially intense. There is horizontal and vertical flexibility. One person may work in parallel on more than one project, taking a different role in each of these. S/he may be the boss, or the project manager in some projects, to then take a more marginal role in others. 
S/he may sometimes offer her/his expertise, some others seeking expertise. Interruptions and distractions are the fabric of such a multi-tasking work, driving away from reflection to action.

Work is mentally demanding and implies responsibility. It is made of often quite new activities to be performed in unfamiliar settings. In these days, markets are characterised by uncertainty, consequently work goals are never clear or defined, and the value of work depends by its originality.

\section{Disability as limitation of activity}

Work transformation clearly affects also the inclusion of disabled people at work. And it has not gone unnoticed by the World Health Organisation (WHO), that in twenty years has changed the basic definition of disability.

In 1980, WHO introduced a clear distinction among impairment, disability, and handicap, and for each term listed various categories, with the relating characteristics, in order to make a classification. It could be interesting to review some of these categories. 'Impairments' are related to the capacity of a person: intellectual, psychological, linguistic, auditory, visual, skeletal, and so on. 'Disability' is connected with the activities performed by a person: behaviour, communication, taking care of oneself, dexterity, and so on. Finally, 'handicap' reveals itself as a deficiency in physical autonomy, work, social inclusion, and economic autonomy of a person. For example, according to these definitions, a blind person is a person who suffers from a visual impairment, which causes a communicative and locomotive disability; it means also handicap, for example, in the mobility and in the occupation. Therefore, one type of impairment can cause various disabilities and involve different handicaps. In a similar manner, one type of handicap can be linked to different disabilities, which can derive from various impairments.

While the impairment is permanent for a person, disability depends on the activities that he/she has to do and the handicap expresses the disadvantage that he/she has with regard to others (so called "normal people"). The significant aspect of the first document of the WHO was that it associated the state of a person not only to functions and structures of the human body, but also to individual activities. The key concept is 'normality'. The degree of handicap is defined with reference to the standard (the one given to "normal people"): It is the gap that must be overcome to become normal.

It is apparent that 1980 definitions of WHO were basically coherent with the work of that time. There are a lot of different jobs. Each one is executed in a standard way. Handicap underlines the gap from the "normal" mode of working caused by the disability. The inclusion of a disable person will be easier as the gap is smaller. There are even jobs where the work is not affected by an impairment at all. For the blind people, the occupation of telephonist is one of these. The new Information Technology sector seemed to be one area where many impairments are insignificant.

In June 2001, the WHO published "Classification of Functioning, Disability and Health". The title is indicative of substantial changes. The aim was no more to describe the handicap, but the state of wellbeing of a person, by focusing on her/his own physical state, but also on the different ways that a person interacts with the outside world, and the impact of external events on a person. There is no reference to any disorder, structural or functional, without linking it to the state of 'wellbeing'. 
Therefore the WHO classification includes not only the physiological and cognitive functions (mental, sensorial, vocal, immunological and cardiological functions, etc.) and the physical structure of a person (the nervous, visual and auditory systems, the vocal apparatus, the cardiovascular and respiratory systems, etc.), but also the activities that guarantee inclusion and social participation (learning, communication, interaction and interpersonal relations, community life, etc.), and environmental, i.e. natural (the environment), artificial (technology), and social (support, attitude, services, etc.) factors. The classification system covers every aspect of human health, arranging them in two different domains. The first is the health domain, which includes the action of seeing, hearing, walking, learning and remembering, etc. This is directly related to physical structure and functions. The second, the health-related domain which includes mobility, education, participation in social life and similar, refers to activities and environmental and social factors.

It is important to underline that the WHO definition does not only concern persons with disability but everybody: it has a universal use and value. There are hundreds of different categories. Any person can be associated with one or more categories that characterise his/her 'functioning'. The classification is 'positive'. It starts from the 'normal' level of functioning, considers if a person differs from this norm, and how far they are from it. The term 'handicap' is abandoned and the term 'disability' is extended to cover the limitation of activity and restriction on participation. For the function and structure of the body, the qualifier can assume values from zero (no impairment) to four (severe impairment, equal to 96-100\%). Similar qualifiers exist for the activities that do not refer to impairment, but to limitations, and for participation it is said that there are restrictions. In short, concerning environmental factors there are barriers.

In our view, the new WHO definitions and classifications are strongly related with the changes in work (not to say in the attitudes of disabled people toward them) that had taken place during the years. Moreover, all this has been strongly influenced by the information technology. In summary, handicap is now seen as a form of diversity in a society where all are diverse and need some kind of assistance.

\section{5. $\mathrm{HCl}$ as science of diversity}

It is work itself that demands for an increased diversity, because it has become more complex, more technology enmeshed, because it mixes the traditionally separated moments and spaces of work life and personal life.

Disabilities have to be seen as some of the forms of diversity we should take care of, since, as for technologies, difficulties and benefits concern everyone. It depends on the tool, and the context. Difficulties can arise or change at any time; it is not possible to overcome them once and for all. This perspective implies the concept of disability must be replaced by the idea of diversity. From the point of view of diversity, people have not to be qualified as disabled, but rather as more or less diverse from others with respect to their working situation and the degree of their IT competence (Hull, 2004). Everyone is, in a way, disabled with respect to digital technology. To overcome their personal digital divide (subjective and contextual), everyone needs to personalise technology (Obrenovic et al., 2007). The needs of disabled people are cases in the general necessity to personalise IT. But every person, either normal or disabled, continually needs more personalised and specific solutions. Disabled people 
may live in greater symbiosis with technology, so they are probably the most evident case of human-machine symbiosis.

The challenge for HCI (in other words, the demand that society is posing on $\mathrm{HCI}$ ) is to turn itself into a science of diversity and to achieve a smooth interplay between user studies and design. This transition has not been completed yet, even though it is acquiring increasing importance in the HCI community (Harper et al., 2008). In this section, we will briefly sketch the main open issues that, in our opinion, HCI has to address to turn itself into a science of diversity. We will present three aspects:

- $\quad$ From work to self-realisation

- $\quad$ A new pace of learning

- Digital ecosystems

\subsection{From work to self-realisation}

Ergonomic studies were initially born to address work-related problems. Work was conceived of as physical and mental strain, which is for instance reflected in the French word for work 'travail', literally 'toil', 'pain'. Ergonomics set out to reduce or eliminate this pain. In the Nineteen century, machines entered workplaces, thus becoming the first source of strain. It was by interacting with machines that humans started working in unhealthy conditions (e.g. high temperature, dirtiness, noise, etc.), also at risk of being killed or seriously harmed by the machine itself. This is why ergonomics traditionally considers human-machine interaction as the locus where work-related problems are engendered.

The approach has been changing in the last few years. HCI needs to address not only workrelated problems, but it should also cover leisure and entertainment (Bodker \& Sundblad, 2008). HCI researches now need to go beyond 'human needs' and also focus on 'desires'. People nowadays engage in interactions with the machines not only to work, but most of all for the experience of it, to fulfil personal goals and desires. HCI cannot restrain itself to merely correcting interaction problems, it has to contribute to the creation of fulfilling experiences. The Apple iPod does not solve any music-related problem. It instead leverages on the experience of listening to our favourite music.

The same reasoning should apply to $\mathrm{HCI}$ and disabilities. HCI should not be primarily focused on solving impairments, it should also include in its objectives the creation of rewarding experiences of use (Yesilada et al., 2007). In a recent interview, Donald Norman aptly pointed out that assistive devices should be also aesthetically pleasing ("CNN Designers challenged to include disabled", available on the Web on Norman's site www.jnd.org/). If we consider social networks the reasoning is straightforward. A social network is valuable not because of its usability, but because it serves as an attracting pole for a community of people (Hart, 2008). This source of value does not change if an user interacts with it with the aid of assistive technologies.

Gaming is another case of such a general change of approach. HCI researches on gaming cannot primarily concentrate on functional aspects of the interaction (Desurvire et al., 2004). Game interfaces are windows on complex set of activities. Users enter game world through the interface. The interface is the access door to an ongoing narration, which is nowadays often a collective one.

HCI has not completed yet this transition, from an applied science of correction to the science of analysing and designing rewarding human-machine interaction. Many researches are going in this direction (Garrett, 2002; Lundgren, 2008; McCarthy \& Wright, 2004). 
However, design is still considered by many as a form of art, while HCI methods and techniques mostly provide support for the evaluation of technologies, or for activity analysis (Norman, 2006).

\subsection{A new pace of learning}

A second challenge for $\mathrm{HCI}$ comes from the current pace of change. We are not only referring to technological innovation. We are mostly concerned with the rate of change of human desires. If $\mathrm{HCI}$ had to correct interaction problems, we may expect these problems to be fairly stable. That is why we have design heuristics and principles. Desires are instead by their very nature dynamically changing, as they are referred to the whole of a person, including social relationships, values and culture. Desires concerns one's own lifestyle, thus making their nature a really dynamic one. One person may even have contradictory desires, subject to drastic changes over time. Desires' development proceeds by leaps, hard to predict, not at all in linear trends.

A side effect of such a dynamic is that new desires fade away as quickly as they have emerged. This has a cost for both HCI research and for users themselves. HCI has to be ready to address new desires, to move away from them as they become less relevant, to pick up new challenges. Which often implies adopting different sets of methods and techniques. On the other hand, users invest their time in learning how to interact with a tool, to then relearn its new releases, to eventually start again from scratch in case another tool becomes available. This require HCI to support new learning styles and paces. Users no longer progress from a present-at-hand modality to ready-to-hand modality in a linear way (to then eventually devote their time to fully master the tool). Learning is not only a vertical process of progressively mastering a fixed body of knowledge. It is also a horizontal movement of transcending domain boundaries. As well put by Engeström (Engeström, 1987), the crucial learning activity for experts is learning what is not yet there. Users need to learn how to move from one tool to a new one in a quick and efficient manner.

There are two key points in the above line of reasoning. On the one hand, learning has changed its nature by becoming more transversal and dynamic, which requires users and researchers to be highly flexible. On the other hand, the actual bottleneck in such learning dynamics is represented by our attentional resources, scarce by nature. Our society is increasingly characterised by a fierce competition for attention. Different inputs are competing for the attention of users, customers, audience, etc. (Bagnara, 2008; Davenport \& Beck, 2001). The consequence is that the turn-over among different inputs is very fast, while it gets risky to actually invest lot of resources (attention and memory) in any of them. We may pick a totally wrong "investment", but even if we select the right one, we may end up having a too short time to actually profit from it. There is no point in becoming a proficient Facebook user, if another social network is likely to take its place in two-three years (or even less). Users and researchers then need to devise new strategies to manage their attentional resources.

The line of reasoning for disability should be similar. Users need to learn how to adapt to assistive devices' rate of change. HCI has to adapt its methods and techniques to such a pace, possibly supporting users in the continuous learning activity required by innovation. Disable people see the continuous change in the technologies, in the way they have to interact with them, in the skills needed to operate with them, and in the knowledge required to understand them as requiring an endless effort to cope with (Bagnara \& Failla, 2007). But 
most of all, we would need more disciplined ways of supporting users in managing their attentional resources. The use of aggregators of social preferences (e.g. like Trip Advisor, Delicious, Stumble Upon, or the Amazon's recommending system) is just a first instance.

\subsection{Digital ecosystems}

The third issue impacts directly on the already mentioned movement that an user does from a present-at-hand modality to ready-to-hand modality. Ubiquitous computing (and Ambient Intelligence) means a more pervasive presence of computer, but it may also bring by a qualitative change in the interaction type. Computers will start interacting with each other, often independently from any user's input. Will this digital ecosystem ever be present-athand?

As mentioned above, some HCI researchers maintain that "a good tool is an invisible tool". This may be true in many respects, but what about the perceived degree of control over technologies? What about troubleshooting activities? How can we form our model of the system functioning, if the system works almost independently from our inputs? Both degree of control and troubleshooting rely to a large extent on the present-at-hand modality, on conscious analysis and reflection. If computers are invisibly weaved into our world and if they start to invisibly interact with each other, the user is likely to have little (if any) visibility on their behaviour. We may also expect this complexity to cause emerging properties, even hard to detect and to intervene on in case needed.

The challenge for $\mathrm{HCI}$ is to analyse and design human-computer interactions, computercomputer interactions, but most of all the degree of control that users should have on these digital ecosystems. We would need to design new interfaces to enable control of digital ecosystems, to represent their state in a comprehensible manner and support intervention. For instance, Smart Homes (and other applications of Ambient Intelligence) are often based on "smart monitoring" of people living therein, but they afford humans limited control on the system. Sensors are deployed in home environment to monitor movements, to track behaviours and interactions with household objects (Kimel \& Lundell, 2007), to detect potential critical incidents (de Ruyter \& Pelgrim, 2007). A sense of tele-presence is created, but the real users of these systems are seldom those being monitored. They serve to caregivers, or family members, or therapists and doctors. Self-monitoring is seldom implemented, direct control over Ambient Intelligence almost never.

There is a second issue at stake here: users may end up 'dovetailing too much' to the digital ecosystem, thus losing their capacity to switch to a present-at-hand modality. We have the case today of too ready-to-hand tools in the form of 'technological addictions' (Young, 1998). For instance, email monitoring has become a task in itself for many office workers, instead of being a communication tool (Renaud et al., 2008). In this case, it seems we have lost the capability of reflecting on the tool. The tool is "too transparent". Instead of getting in our way while we try to communicate with fellow colleagues and friends (thus stimulating reflection), it directs our behaviour on the basis of its rhythms (i.e. it checks email every five minutes), creating a Narcissus effect.

Disability and assistive technologies are again a "not that special" case of the above dynamics. Assistive technologies often form a deeper symbiosis with their users, so HCI needs to pay a special attention to loss of control, invisibility, Narcissus effects. Our claim here is not that we should avoid designing for the ready-to-hand modality, rather that $\mathrm{HCI}$ 
should devise methods and techniques to explore the tensions between the two modalities and find means to identify the appropriate trade-off.

\section{6. $\mathrm{HCl}$ porous borders: personalisation as the overlap of diversity and disability}

One of the avenues that HCI has been more actively pursuing to address the goal of designing for diversity is that of personalisation. Personalisation addresses diversity of users by means of malleable tools, that can shaped as preferred by each user, for instance by changing the interface layout, activating special features, providing automation for frequently performed actions. Some computer applications do not even require the user intervention to adapt, as they self-modify themselves by tracking the user's frequent behaviours. For instance, Microsoft Office cascade menus automatically "shorten" themselves, displaying only those options that have been frequently chosen by the user.

It should then not come as a surprise that the main claim of this contribution is to a large extent already true in the area of personalisation. When we discuss the need to personalise technology, there is no 'HCI for disabled people' versus 'HCI for normal people'. The need is the same, maybe just more pressing for assistive technologies, probably with some additional constraints. HCI research on the personalisation of assistive technology can be rightly conceived as research on diversity, and for this very reason it often has a fallout on domains different than assistive technologies.

However, as far as disability is concerned, the need for personalisation has to be addressed at a qualitatively different level. This is not because disabled people possess qualitatively different needs and preferences than the "normal user" (this is exactly the assumption we are arguing against in this contribution). The point is that disability adds a further level of complexity to human-computer interaction, by introducing an additional source of changes in the user's preferred interaction modalities. A source that is complex and very dynamic for two main reasons. Firstly, users do not only show a variety of disability. Many experience a combination of disabilities, especially when combined with aging. Secondly, users' needs fluctuate in time, both in the long term because of aging, but also in the short term, due to fatigue or other immediate needs. As well put by Hanson and Richards (Hanson \& Richards, 2005) "users have complex, interacting, and changing abilities". HCI has then to address 'dynamic diversity' (Gregor et al., 2002; Hanson \& Richards, 2005), which means fluctuations in time and combination of different disabilities.

To summarise the line of argument in few words: each user has some preferred ways of interacting with her/his computer, which may change driven by needs, desires or everyday contingencies. Personalisation addresses such differences and changes. Disability can be conceived as another source of change in the user's favoured interaction modalities, one which brings about very dynamic and significant changes. And so it is ageing.

To demonstrate such a contiguity between $\mathrm{HCI}$ research on disability and $\mathrm{HCI}$ research in general, the rest of this section will discuss cases of personalised applications/technologies that successfully flourish (or have flourished) in the assistive technology domain and beyond it. 


\subsection{When an accessible system is a better systems}

The first case shows how ergonomic improvements introduced to accommodate disabled workers may engender a beneficial fallout also for non-disabled workers. Seated working positions are nowadays common in assembly line production. However, their first appearance was due to the duty for employers to modify or adjust work to accommodate disabled workers. In a famous case from the Seventies (an assembly line of an Alfa Romeo factory), such a modification initially brought to two separate assembly line working positions, the seated one for disabled people and the standing one for the "normal worker". One system for disabled, one for non disabled. But it did not take long for non disabled people to realise that the seated position could actually bring some benefits to them as well, in terms of comfort and work-related physical strain. So, unless in those cases where other ergonomic considerations suggested not to do so, the whole assembly line was restructured according to the seated position. Ergonomics research on disability had been a driver to improve well being for all the workers.

Another case is mentioned in (Hanson \& Richards, 2005). The authors present a system to improve web accessibility for people with limited dexterity and vision. Over-summarising for clarity's sake, the system magnifies web pages to ease navigation and reading. In order to do so, it has to be able to distinguish the various parts of a page, to selectively magnifies those that convey information of actual interest to the user. For instance, it needs to distinguish between the navigation bar and the page main content, in order to render the page with less visual clutter and fewer navigation options. The system can use the 'skip navigation tag' for this purpose, a HTML tag initially conceived as a way for screen readers (for blind people) to skip directly to the main content on a page. "the skip navigation tag also allows our software to do a better job of rendering pages for low vision users [...] These are examples in which conformance to standards and guidelines results in a more usable page for those not using the initially targeted assistive device. Thus, rather than eliminating the need for accessibility markup, our software capitalizes on its presence to give any person a more useable Web page" (idem, pg. 245).

\subsection{Beyond mouse and keyboard: research on multimodality}

A second group of examples relates to HCI research on multimodal interaction. This field covers research on input methods different than those based on keyboard and mouse, the application of which spans from mass market product to assistive devices (for a review see Hinckley, 2009; Samman \& Stanney, 2006). To name but the principal research areas, interfaces based on speech recognition, pointing, gaze direction or gesture recognition can be exploited to ease human-computer interaction for people with reduced dexterity or motor impairments, but can also be implemented to support hands-free tasks, for instance to reduce risk of infections in pre-operatory debriefs for surgeons, during operations to cut operation time, to have a military aircraft pilot fly the aircraft while gaze-pointing at a target. Another particular case is that of Brain-Computer Interfaces, where the user may self-regulate brain activity (detected by the EEG - electroencelogram - electrical activity of the brain) in order to move a cursor on the computer screen. Again, this interaction modality is an alternative to conventional input devices, which may be particularly useful for people with disabilities. But it can be also used in other situations, not related to assistive technologies. 
Unlike the previous assembly line case, these are not cases of assistive technologies fallout to other application domains. Rather we observe concurrent research efforts on the development of a specific set of technologies, whose characteristics may suit the diversity of different users/activities (i.e. particular conditions of operations, or disabled people).

Under the same category, we may also mention 'sonification', i.e. the use of nonspeech audio to convey information. "Sonification is typically used in situations where the user's eyes are busy elsewhere, such as in a laboratory or production line; where extracting temporal information is important; or where the data presentation requirements exceed the bandwidth of visual means" (Walker \& Kramer, 2006). Successful applications can be found in the healthcare domain (for instance the hearth rate sound during surgery), or to convey additional information in Geographic Information Systems (e.g. abrupt changes in height or depth). The same technique is also exploited in assistive devices, typically for visually impaired users, for instance to support the exploration and construction of graphs and diagrams (Metatla et al., 2008), or the interaction with computer devices (Yalla \& Walker, 2008).

The last example we would like to briefly mention for multimodal interaction is that of gesture-based interaction. On the one hand, gesture research is a natural province of research on technology accessibility. For instance, compared to point and touch interfaces, gesture-based interfaces are easier to use by people with diminished visual acuity (Kane et al., 2008; Moffatt et al., 2008). Research on Sign Languages (and by extension assistive technologies based on Sign Languages) is also concerned with gestures (Huenerfauth, 2008). On the other hand, the iPhone interaction modality (based on gestures, rather than on touch) has brought gesture-based interfaces to the mass public.

\section{The niche and beyond: new (economic) drivers for assistive technologies?}

We have discussed in the preceding sections how $\mathrm{HCI}$ is now facing the challenge of an ever increasing diversity. HCI application fields are not stable at all, they cover a large variety. This means an enlarged scope for HCI research. It also means including human values in HCI leading principles. Technologies are not neutral, they have an impact on social and cultural values. Such an impact is probably the only sensible criterion to steer design. This is similar to the shift from a technology-driven approach to an user-centred one, provided that we complement the old-fashioned criteria (e.g. efficacy, efficiency, usefulness) with social ones. HCI should be able to analyse the multi-faceted issues brought by technological innovation, be those of a cultural, social, political, or even ethical nature. From technologydriven, to user-centred, to human-centred.

To address this change, Harper et al. (Harper et al., 2008) suggested that HCI should focus on two immediate challenges. Firstly, user-centred design should explicitly include the analysis of social issues in the development process, in order to design human-centred innovation. Secondly, HCI should develop methods and techniques to foster dialogue with the humanities. Design trade-off are likely to increasingly concern socio-cultural aspects, with their large variation across different contexts and communities (Medhi, 2007). The concept of privacy means something different in our workplace or in our family, in a small town or in big cities.

$\mathrm{HCI}$ no longer studies the interaction between technology and an undifferentiated user (that has to be defined as broadly as possible to fit anybody), rather we need tools to address every user's needs and diversity. Even very peculiar ones. 
A potential pitfall here is that of designing overly specific solutions. While it is true that every user is different, it is not feasible to have a different design solution for each one. HCI should work on disciplined ways of overcoming the gap between users and design. Disciplined ways of considering the user characteristics, using them as design leverages, and at the same time being able to identify unnecessary peculiarities. Possibly designing userfriendly tool personalisation, so that each user can customise to a certain extent the tool.

Design to overcome handicaps has been until now (for the large majority) a clear case of over-peculiar innovations, that is innovations that could not benefit any other user than the ones initially targeted. Our proposal is to consider it no longer as a niche, but rather as the most challenging endeavour of a widespread, general approach: dovetailing with diversity to design human-centred innovations (Marcus, 2003). Disability can be regarded as one among many sources of change in the user's favoured interaction modalities.

'Limitation of activity' and 'restriction on participation' are two key concepts not only for disabilities, but also for $\mathrm{HCI}$ in general. They are not only related to physical, cognitive or social impairments, but also strongly due to the changing nature of society, work and IT use. If HCI succeeds in this transition, the disability niche may eventually turn into a research intensive one, not solely devoted to assisting a minor part of the population, not to design and manufacture devices that are of some use only for disabled people, rather to function as an incubator for potentially profit-earning innovations. HCI has always been characterised by the successful fallout of technologies from one application to other ones, typically carrying out research in research intensive domains like the military, the industry, or transportation systems, to then transfer those innovations to mass-markets. This dynamic has increased HCI capability of attracting budget for its researches. The assistive technologies niche may become one of these research intensive niches, where research, pressured by complex problems, makes unexpected developments, devises solutions and then transfers them to other domains. Researchers in this niche should be well equipped to address the ever increasing diversity of contemporary society, and to devise effective ways of dovetailing with it.

\section{References}

Association for Computing Machinery (2008). Definition of HCI, Retrieved August, 2008, from http://sigchi.org/cdg/cdg2.html

Bagnara, S. (2008). L'economia dell'attenzione. In: Attenzione e cognizione, R. Nicoletti, E. Ladavas \& P. Tabossi (Eds.), Il Mulino, Bologna, Italia

Bagnara, S. \& Failla, A. (2007). From Handicap to Diversity. In: Lecture Notes in Computer Science, Vol. 4554, pp. 613

Bateson, G. (1972). Steps to an Ecology of Mind, Ballantine, New York, NY

Bauman, Z. (2000). Liquid modernity, Polity Press, Cambridge, UK

Bodker, S. \& Sundblad, Y. (2008). Usability and interaction design-new challenges for the Scandinavian tradition. Behaviour and Information Technology, 27, 4, 293-300

Chalmers, M. (2004). A Historical View of Context. Computer Supported Cooperative Work, 13, $3,223-247$

Clark, A. (2003). Natural-Born Cyborgs: Minds, Technologies, and the Future of Human Intelligence, Oxford University Press, Oxford, UK 
Davenport, T. H. \& Beck, J. C. (2001). The Attention Economy: Understanding the New Currency of Business, Harvard Business School Press, Cambridge, MA

Davis, S. \& Meyer, C. (1998). Blur: The Speed of Change in the Connected Economy, Warner Books, New York, NY

de Ruyter, B. \& Pelgrim, E. (2007). Ambient assisted-living research in carelab. interactions $14,4,30-33$

Desurvire, H.; Caplan, M. \& Toth, J. A. (2004). Using heuristics to evaluate the playability of games, Proceedings of Conference on Human Factors in Computing Systems, pp. 15091512, New York, NY

Dourish, P. (2001). Where the Action Is: The Foundations of Embodied Interaction, Mit Press, Cambridge, MA

Engeström, Y. (1987). Learning by expanding: an activity theoretical approach to developmental research, Orienta, Helsinki, Finland

Garrett, J. J. (2002). The Elements of User Experience: User-Centered Design for the Web, New Riders Publishing, Thousand Oaks, CA

Gregor, P.; Newell, A. F. \& Zajicek, M. (2002). Designing for dynamic diversity: interfaces for older people, Proceedings of ASSETS - 4th international ACM SIGACCESS conference on Computers and Accessibility, pp. 151-156, Edinburgh, Scotland

Hanson, V. L. \& Richards, J. T. (2005). Achieving a more usable World Wide Web. Behaviour $\mathcal{E}$ Information Technology, 24, 3, 231-246

Harper, R.; Rodden, T.; Rogers, Y. \& Sellen, A. (Eds.). (2008). Being Human: Human-Computer Interaction in the year 2020. Cambridge, UK: Microsoft Research Ltd.

Hart, J. (2008). Exploring the Facebook experience. Interfaces, 77,

Hinckley, K. (2009). Input Technologies And Techniques. In: Human-Computer Interactions. Fundamentals, A. Sears \& J. A. Jacko (Eds.), pp. 137-152, Taylor \& Francis, Boca Raton, FL

Huenerfauth, M. (2008). Evaluation of a psycholinguistically motivated timing model for animations of american sign language, Proceedings of ASSETS - 10th international ACM SIGACCESS conference on Computers and Accessibility, pp. 129-136, Halifax, Nova Scotia, Canada

Hull, L. (2004). Accessibility: it's not just for disabilities any more. interactions, 11, 2, 36-41

Hutchins, E. (1995). Cognition in the wild, MIT Press, Cambridge, MA

Kane, S. K.; Bigham, J. P. \& Wobbrock, J. O. (2008). Slide rule: making mobile touch screens accessible to blind people using multi-touch interaction techniques, Proceedings of ASSETS - 10th international ACM SIGACCESS conference on Computers and Accessibility, pp. 73-80, Halifax, Nova Scotia, Canada

Kimel, J. \& Lundell, J. (2007). Exploring the nuances of Murphy's Law---long-term deployments of pervasive technology into the homes of older adults. interactions, $14,4,38-41$

Kirsh, D. (1995). The intelligent use of space. Artificial Intelligence, 73, 1-2, 31-68

Lewis, C. (2006). HCI and cognitive disabilities. interactions, 13, 3, 14-15

Lundgren, S. (2008). Designing games: why and how. interactions, 15, 6, 6-12

Malone, T. W. (2004). The Future of Work: How the New Order of Business Will Shape Your Organization, Your Management Style, and Your Life, Harvard Business School Press, Cambridge, MA 
Marcus, A. (2003). Fast forward: Universal, ubiquitous, user-interface design for the disabled and elderly. interactions, 10, 2, 23-27

McCarthy, J. \& Wright, P. (2004). Technology as experience. interactions, 11, 5, 42-43

Medhi, I. (2007). User-Centered Design for Development. interactions, 14, 4, 12-14

Metatla, O.; Bryan-Kinns, N. \& Stockman, T. (2008). Constructing relational diagrams in audio: the multiple perspective hierarchical approach, Proceedings of ASSETS - 10th international ACM SIGACCESS conference on Computers and Accessibility, pp. 97-104, Halifax, Nova Scotia, Canada

Moffatt, K.; Yuen, S. \& McGrenere, J. (2008). Hover or tap?: supporting pen-based menu navigation for older adults, Proceedings of ASSETS - 10th international ACM SIGACCESS conference on Computers and Accessibility, pp. 51-58, Halifax, Nova Scotia, Canada

National Research Council. (1999). The changing nature of work: Implications for occupational analysis. Washington, DC: National Academy of Sciences.

Norman, D. A. (1988). The psychology of everyday things, Basic Books, New York, NY

Norman, D. A. (2006). Interaction design is still an art form: ergonomics is real engineering. interactions, 13, 1, 45-60

Obrenovic, Z.; Abascal, J. \& Starcevic, D. (2007). Universal accessibility as a multimodal design issue. Communications of the ACM, 50, 5, 6

Renaud, K.; Ramsay, J. \& Hair, M. (2008). Think before you link: controlling ubiquitous availability. interactions, 15, 6, 65-68

Samman, S. N. \& Stanney, K. M. (2006). Multimodal Interaction. In: International Encyclopedia of Ergonomics and Human Factors, W. Karwowski (Ed.), Taylor \& Francis, Boca Raton, FL

Vygotsky, L. S. (1978). Mind in society : the development of higher psychological processes, Harvard University Press, Cambridge, MA

Vygotsky, L. S. (1986). Thought and language, MIT Press, Cambridge, MA

Walker, B. N. \& Kramer, G. (2006). Sonification. In: International Encyclopedia of Ergonomics and Human Factors, W. Karwowski (Ed.), Taylor \& Francis, Boca Raton, FL

Weiser, M. (1991). The Computer for the 21st Century. Scientific American, 265, 3, 94-104

Weiser, M. (1994a). Creating the invisible interface, Proceedings of ACM Conference on User Interface Software and Technology (UIST94), New York, NY

Weiser, M. (1994b). The world is not a desktop. interactions, 1, 1, 7-8

Yalla, P. \& Walker, B. N. (2008). Advanced auditory menus: design and evaluation of auditory scroll bars, Proceedings of ASSETS - 10th international ACM SIGACCESS conference on Computers and Accessibility.

Yesilada, Y.; Stevens, R.; Harper, S. \& Goble, C. (2007). Evaluating DANTE: Semantic transcoding for visually disabled users. ACM Transactions on Computer-Human Interaction, 14, 3, 30

Young, K. S. (1998). Internet Addiction: The Emergence of a New Clinical Disorder. Cyberpsychology and Behavior, 1, 237-244 


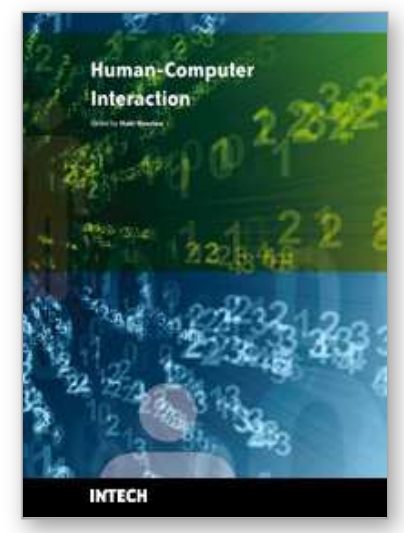

\section{Human-Computer Interaction \\ Edited by Inaki Maurtua}

ISBN 978-953-307-022-3

Hard cover, 560 pages

Publisher InTech

Published online 01, December, 2009

Published in print edition December, 2009

In this book the reader will find a collection of 31 papers presenting different facets of Human Computer Interaction, the result of research projects and experiments as well as new approaches to design user interfaces. The book is organized according to the following main topics in a sequential order: new interaction paradigms, multimodality, usability studies on several interaction mechanisms, human factors, universal design and development methodologies and tools.

\section{How to reference}

In order to correctly reference this scholarly work, feel free to copy and paste the following:

Sebastiano Bagnara and Simone Pozzi (2009). The Continuity of Disability, Diversity and Personalisation: an Emerging Challenge for $\mathrm{HCl}$, Human-Computer Interaction, Inaki Maurtua (Ed.), ISBN: 978-953-307-022-3, InTech, Available from: http://www.intechopen.com/books/human-computer-interaction/the-continuity-ofdisability-diversity-and-personalisation-an-emerging-challenge-for-hci

\section{INTECH}

open science | open minds

\section{InTech Europe}

University Campus STeP Ri Slavka Krautzeka 83/A 51000 Rijeka, Croatia Phone: +385 (51) 770447

Fax: +385 (51) 686166 www.intechopen.com

\section{InTech China}

Unit 405, Office Block, Hotel Equatorial Shanghai No.65, Yan An Road (West), Shanghai, 200040, China 中国上海市延安西路65号上海国际贵都大饭店办公楼 405 单元

Phone: +86-21-62489820

Fax: +86-21-62489821 
(C) 2009 The Author(s). Licensee IntechOpen. This chapter is distributed under the terms of the Creative Commons Attribution-NonCommercial-ShareAlike-3.0 License, which permits use, distribution and reproduction for non-commercial purposes, provided the original is properly cited and derivative works building on this content are distributed under the same license. 